medRxiv preprint doi: https://doi.org/10.1101/2021.03.04.21252917; this version posted March 8, 2021. The copyright holder for this preprint (which was not certified by peer review) is the author/funder, who has granted medRxiv a license to display the preprint in perpetuity. All rights reserved. No reuse allowed without permission.

\title{
Social-distancing Fatigue: Evidence from Real-time Crowd-sourced Traffic Data
}

\author{
Jenni A. Shearston, Micaela E. Martinez, Yanelli Nunez, Markus Hilpert
}

Department of Environmental Health Sciences

Mailman School of Public Health, Columbia University

722 West 168th St.

New York, NY 10032

Corresponding Author

Jenni A. Shearston

js5431@cumc.columbia.edu 
medRxiv preprint doi: https://doi.org/10.1101/2021.03.04.21252917; this version posted March 8, 2021. The copyright holder for this preprint (which was not certified by peer review) is the author/funder, who has granted medRxiv a license to display the preprint in perpetuity.

All rights reserved. No reuse allowed without permission.

20
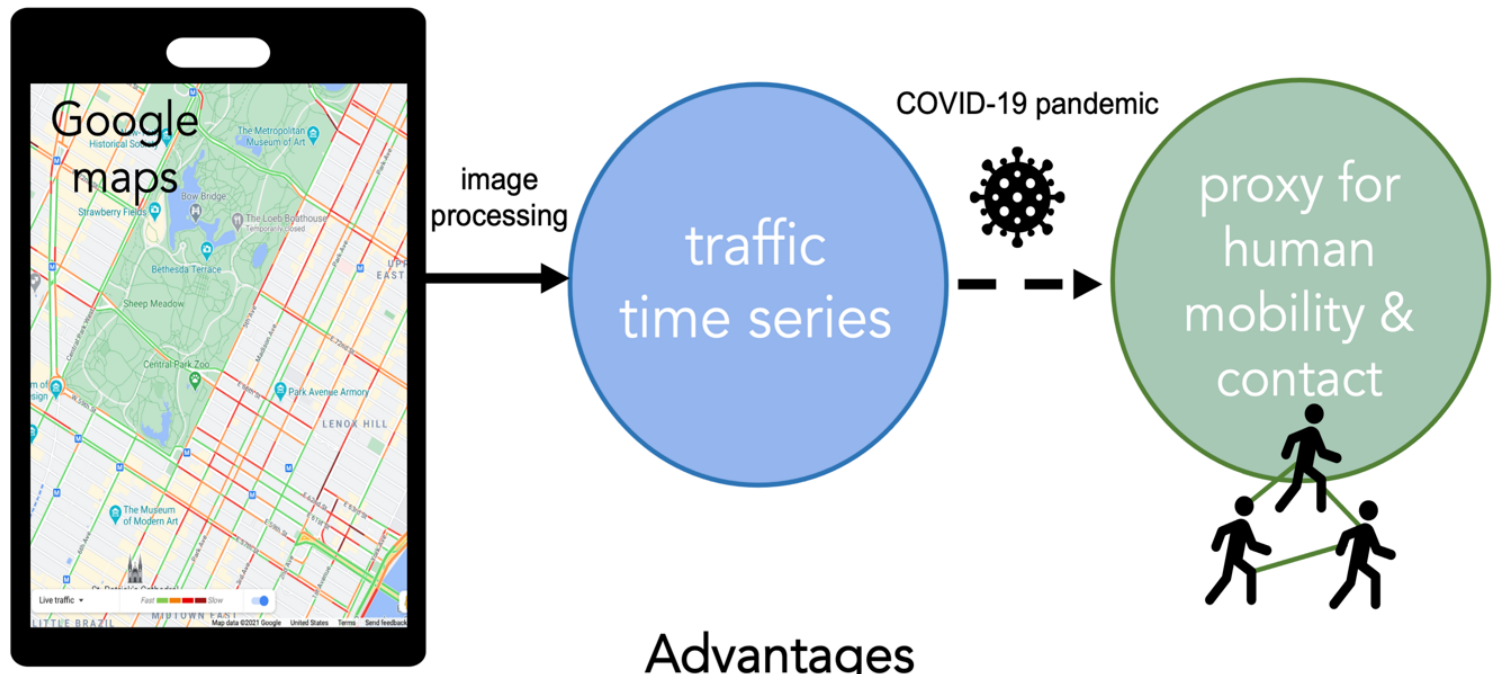

Advantages

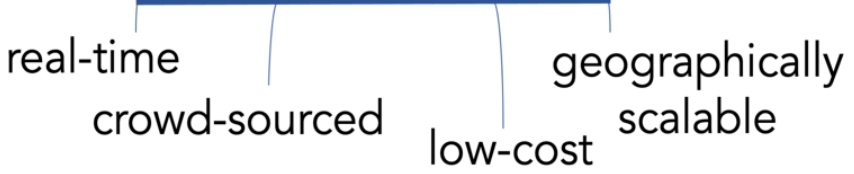




\section{ABSTRACT}

Introduction: To mitigate the COVID-19 pandemic and prevent overwhelming the healthcare system, social-distancing policies such as school closure, stay-at-home orders, and indoor dining closure have been utilized worldwide. These policies function by reducing the rate of close contact within populations and results in decreased human mobility. Adherence to social distancing can substantially reduce disease spread. Thus, quantifying human mobility and socialdistancing compliance, especially at high temporal resolution, can provide great insight into the impact of social distancing policies.

Methods: We used the movement of individuals around New York City (NYC), measured via traffic levels, as a proxy for human mobility and the impact of social-distancing policies (i.e., work from home policies, school closure, indoor dining closure etc.). By data mining Google traffic in real-time, and applying image processing, we derived high resolution time series of traffic in NYC. We used time series decomposition and generalized additive models to quantify changes in rush hour/non-rush hour, and weekday/weekend traffic, pre-pandemic and following the roll-out of multiple social distancing interventions.

Results: Mobility decreased sharply on March 14, 2020 following declaration of the pandemic. However, levels began rebounding by approximately April 13, almost 2 months before stay-athome orders were lifted, indicating premature increase in mobility, which we term socialdistancing fatigue. We also observed large impacts on diurnal traffic congestion, such that the pre-pandemic bi-modal weekday congestion representing morning and evening rush hour was dramatically altered. By September, traffic congestion rebounded to approximately $75 \%$ of prepandemic levels.

Conclusion: Using crowd-sourced traffic congestion data, we described changes in mobility in Manhattan, NYC, during the COVID-19 pandemic. These data can be used to inform human mobility changes during the current pandemic, in planning for responses to future pandemics, and in understanding the potential impact of large-scale traffic interventions such as congestion pricing policies.

\section{KEY WORDS}

Traffic maps; human mobility; crowd-sourced data; social-distancing fatigue; coronavirus pandemic 
The COVID-19 pandemic threatens almost every single country on Earth. ${ }^{1,2}$ To curb the pandemic and prevent overwhelming the healthcare system with COVID-19 cases, socialdistancing policies such as school closures, non-essential business closures, curfews, and stay-athome orders have been put into place. Social-distancing policies, specifically quarantines, are some of the oldest and most utilized strategies for epidemic control. ${ }^{3}$ Social distancing policies function by reducing physical contact and decreasing human mobility; adherence can substantially reduce transmission ${ }^{4}$ and case counts. ${ }^{5}$ Thus, quantifying human mobility and social-distancing compliance, especially at high temporal and spatial resolution, is critical for controlling the epidemic.

71

72

73

74
Several measures of social-distancing compliance have been used previously in the literature. Studies evaluating individual-level adherence to social-distancing policies frequently use selfreport through online surveys..$^{6-8}$ While these methods are very useful for evaluating determinants of adherence, they are not as useful for real-time epidemic monitoring because they are time- and labor-intensive and only capture a snapshot of the population's behavior in a small sample at a single timepoint. In contrast, highly resolved data such as mobile phone call records or locations can be used to measure social-distancing ${ }^{9}$ and to inform mobility components of infectious disease transmission models. ${ }^{10}$ These measures, especially if publicly available, can contribute to epidemic monitoring. One such option is vehicular traffic condition smartphone apps, which base their maps on cellphone movement data. Traffic congestion maps are publicly available, updated in real-time, and can be used for public health research. For example, we have previously shown that colors in Google traffic maps correspond to relative vehicle speed, and used this information to infer traffic-related air pollution. ${ }^{11}$

App-based traffic information offers a pathway for assessing social-distancing, as increased traffic congestion is indicative of spending time outside the home that may result in opportunities for human interaction and contact. In fact, traffic data has been used to evaluate mobility during the pandemic in South Korea, finding that in some cities increases in traffic were correlated with increases in cases, but that in others traffic and cases were negatively correlated. ${ }^{12}$ Here we analyzed time series of traffic congestion that we derived from app-based maps. We quantify changes in traffic in the Manhattan borough of New York City (NYC) during the COVID-19 pandemic (January 1 to December 31,2020). Our objective was to describe how social distancing interventions impacted population-level patterns of mobility throughout various stages of the pandemic.

\section{METHODS}

From January 1 through December 31, 2020, we obtained 12 tiles from Google traffic maps to view Manhattan's entire street network every three hours in real-time. We used image processing methods, as described previously in Hilpert et al., ${ }^{11}$ to identify the color-coded road segments. Color codes indicated four traffic categories: (i) green for free-flowing traffic, (ii) orange for medium traffic, (iii) red for traffic congestion, and (iv) maroon for severe traffic congestion. The 
colors are proxies for vehicle speed. ${ }^{11,13}$ In summary, ${ }^{11}$ map pixels for each of the four colors were counted and time series generated of the percent of the map area covered by each color.

To investigate changes in traffic congestion during the pandemic, we first characterized all four time series, but then restricted further analysis to the time series of red traffic congestion given its clear pandemic-related signal (e.g., decrease in April) and simpler interpretability (increases in red coverage indicate increases in congestion). We did this to avoid redundancy in analysis since all color coverage time series showed correlated temporal patterns. There were substantial changes in traffic congestion over the course of the pandemic and we captured this variation by partitioning the time series into four distinct time periods, which we refer to as COVID periods. We individually fit a generalized additive model (GAM) $)^{14}$ to each COVID period.

GAM models were constructed to predict the time series of percentage of total map area covered by traffic congestion, $\left(T_{t}\right)$ using two discrete predictor variables: hour of day, $h_{t}$, which can assume values $0,3,6,9,12,15,18$ and 21 ; and the binary variable $w_{t}$ indicating whether a traffic map describes traffic on weekdays $\left(w_{1, t}\right)$ or during weekends $\left(w_{2, t}\right)$. We fitted the following model to the measured $T_{t}, w_{1, t}, w_{2, t}$ and $h_{t}$ data:

$$
T_{t}=a_{0}+w_{1, t} s_{1}\left(h_{t}\right)+w_{2, t} s_{2}\left(h_{t}\right)+\epsilon_{t}
$$

where $a_{0}$ is the intercept (representing mean color coverage), and $s_{1}$ and $s_{2}$ are cyclic cubic regression splines with 8 degrees of freedom and zero mean. Degrees of freedom were selected using the generalized cross-validation criterion. The fitted models were then used to predict congestion levels hourly for a weekend and weekday, with $95 \%$ confidence intervals. Due to the morning and evening rush hour, traffic congestion displayed a 24-hour periodicity. The range of the diurnal fluctuation was measured as the deviation from the intercept.

To investigate potential social distancing fatigue (increased mobility before relaxation of stay-athome policies), we applied seasonal decomposition of time series by Loess (STL) ${ }^{15}$ to the data from March 14 to June 16, a period including the NY on PAUSE policy intervention and the first stage of New York's reopening (Phase 1). This analysis decomposed the time series into a periodic component, time trend, and the remainder (or residual). Prior to running the analysis, missing observations $(n=54)$ were imputed using predictions from the GAM models.

All analyses were conducted in R version 3.5.1 (R Foundation for Statistical Computing, Vienna, Austria). Simon Wood's mgcv package was used to fit GAMs. ${ }^{16}$ STL analysis was completed using the 'stl' function in the stats package.

\section{RESULTS}

We found abrupt decreases in traffic congestion in Manhattan following school closures and the implementation of stay-at-home orders (NY on PAUSE). For a list of policies implemented by New York State and NYC in response to the COVID-19 pandemic, please see Supplemental Table 1. A map of the study area is shown in Figure 1, with colors representing the crowdsourced traffic data. There was a dramatic decrease in traffic congestion after the implementation 
medRxiv preprint doi: https://doi.org/10.1101/2021.03.04.21252917; this version posted March 8, 2021. The copyright holder for this preprint (which was not certified by peer review) is the author/funder, who has granted medRxiv a license to display the preprint in perpetuity.

All rights reserved. No reuse allowed without permission.

151 of social distancing policies. Stark differences in the proportion of green free-flowing traffic are 152 readily apparent on the ring roads that trace the edges of Manhattan Island, as well as the main 153 entry points, including the George Washington Bridge in the north and all tunnels and bridges in 154 the south.

Time series of the four congestion colors (Figure 2) reveal abrupt decreases in traffic congestion after March 14, the weekend before New York public school closure, with simultaneous increases in free-flowing traffic occurring. Importantly, we observed a steady increase in traffic congestion before New York on PAUSE ended on June 7th. This increase was most apparent in the red traffic congestion series, where traffic congestion appears to begin increasing on approximately May 1 and continues increasing up until about July 1. These increases occur before the end of stay-at-home orders and are indicative of social-distancing fatigue.

163

We identified four COVID Periods where traffic congestion changed markedly and fit each with a GAM model (Equation 1). The Pre-COVID Period was defined as the start of the time series

166 (January 1) through March 13, before congestion began to decrease dramatically. COVID Period 1671 was defined as March 14 through May 19. Around May $19^{\text {th }}$ traffic congestion started to 168 increase to the point that the model began poorly fitting the data; therefore, we defined COVID 169 Period 2, which was May 20 through June 16, during which traffic congestion continued 170 increasing. COVID Period 3 was June 17 through the end of the time series (December 31), 171 where a more stable traffic pattern emerged. 
medRxiv preprint doi: https://doi.org/10.1101/2021.03.04.21252917; this version posted March 8, 2021. The copyright holder for this preprint (which was not certified by peer review) is the author/funder, who has granted medRxiv a license to display the preprint in perpetuity.

All rights reserved. No reuse allowed without permission.
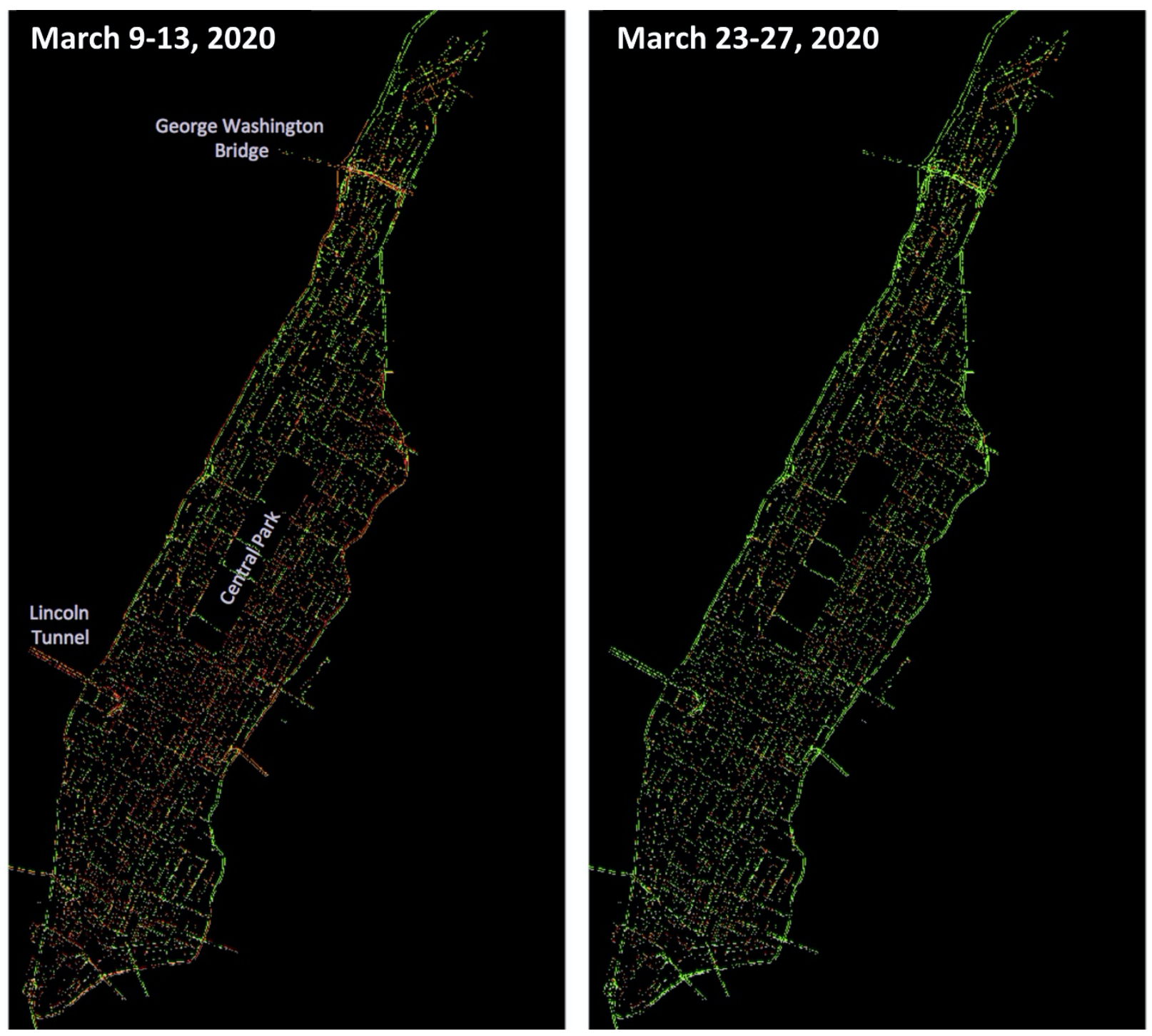

Figure 1. Pre- and Post-Pandemic Traffic. 5-day average traffic congestion in Manhattan during the 9:30 am weekday morning rush before (March 9-13) and after (March 23-27) school closures and stay-at-home orders (NY on PAUSE policies) went into effect in New York City. Red and orange indicates traffic congestion, while green indicates free-flowing traffic. After the implementation of NY of PAUSE policies, traffic became free flowing in the ring roads surrounding Manhattan, as well as the main entry points, including the George Washington Bridge in the north and all tunnels and bridges in the south. 
Figure 2. Time series of the percent of congestion color coverage within Manhattan for the four traffic categories. Vertical black lines delineate COVID time periods for the four separate GAM models, labeled below the bottom xaxis. The timeline of COVID response policies implemented by New York State are outlined at the top of the figure.

Morning and evening rush hour impose a periodic cycle to traffic patterns, seen as daily peaks and troughs in traffic (Figure 2). The pandemic not only caused changes in traffic trends, but also drove changes in the period cycle. In addition to the daily periodicity, there was also a weekly cycle where congestion was elevated during the five consecutive weekdays and was dampened during the two consecutive weekend days. The weekly cycle was most apparent in the Pre-COVID period and in the most recent period, COVID Period 3.

Mean percent area with red traffic congestion changed dramatically throughout the time period (Table 1). Percent area with mean red traffic congestion (equivalent to the model intercept) was highest during the pre-COVID time period, and then decreased abruptly during COVID Period 1 (from a mean of $0.99 \%$ to $0.41 \%$ ) before steadily increasing for COVID Periods 2 and 3 . By COVID Period 3, the mean red traffic congestion area had rebounded to about $75 \%$ of the prepandemic average. 
medRxiv preprint doi: https://doi.org/10.1101/2021.03.04.21252917; this version posted March 8, 2021. The copyright holder for this preprint (which was not certified by peer review) is the author/funder, who has granted medRxiv a license to display the preprint in perpetuity.

All rights reserved. No reuse allowed without permission.

Table 1. Intercepts $a_{0}$ for generalized additive models describing the time series of red traffic congestion coverage $T_{t}$ (\% area) for four time periods during the COVID-19 pandemic

\begin{tabular}{lcc} 
COVID time period & $\boldsymbol{a}_{\mathbf{0}}$ & p-value of intercept \\
\hline Pre-COVID (January 1 - March 13) & 0.99 & $<0.001$ \\
COVID 1 (March 14 - May 19) & 0.41 & $<0.001$ \\
COVID 2 (May 20 - June 16) & 0.56 & $<0.001$ \\
COVID 3 (June 17 - December 31) & 0.74 & $<0.001$
\end{tabular}

The rebound in red congestion coverage began far in advance of the implementation of Phase 1 reopening (Figure 3, second panel). In STL analysis of COVID Periods 1 and 2, congestion appears to increase from approximately April $13^{\text {th }}$ onward, while Phase 1 reopening did not begin until June 8 (right dashed line).
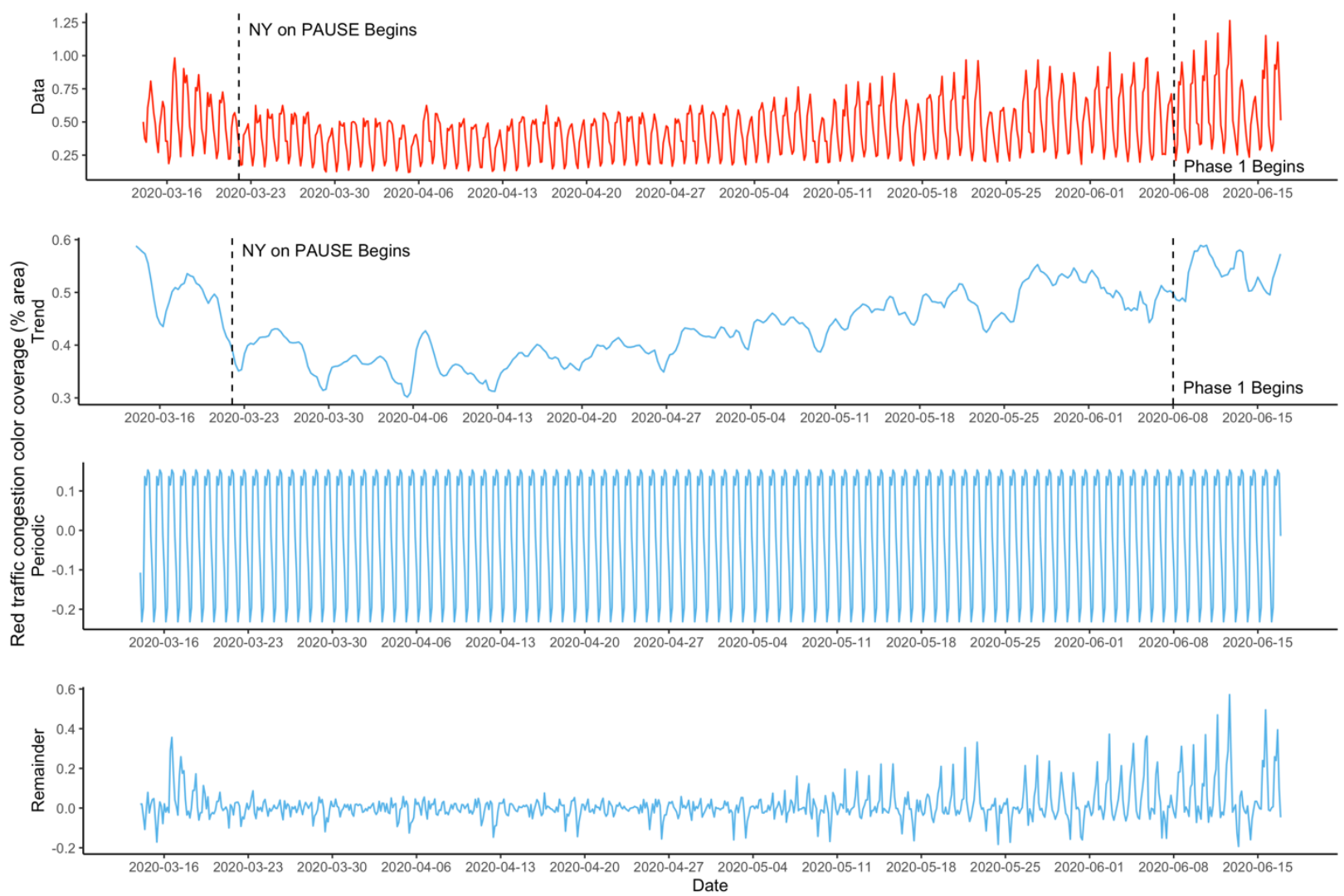

Figure 3. Time series decomposition of red traffic congestion from March 14 to June 16, 2020, with Loess. A time series of the red traffic congestion data is shown in the top panel, while the second panel shows the trend over time, the third panel shows the periodic daily pattern, and the bottom panel shows the remainder (or irregular) components of the time series. Dashed vertical lines indicate dates that policies were implemented to control the spread of the pandemic (left line: NY on PAUSE; right line: Phase 1 Reopening).

In addition to these changes in traffic trends, the pandemic substantially altered daily traffic periodicity, such that during the height of the pandemic in NYC in the Spring, there was little differentiation between weekday and weekend traffic patterns (Figure 4, tan lines). During the Pre-COVID period (grey lines) rush hour peaks were highest, with weekdays demonstrating a 
clear bimodal distribution with peaks around 9am and 5pm, and weekends a clear unimodal peak around 5pm. However, during COVID Period 1, both weekday and weekend traffic peaks were greatly dampened, and the bimodal weekday distribution shifted to nearly unimodal, becoming very similar to the weekend distribution. During COVID Period 2 and 3 the daily traffic peaks were greater than for Period 1, but still lower than pre-pandemic levels. Even as overall traffic increased during these periods, the weekday distribution remained altered, such that the morning peak was much smaller than the evening peak.

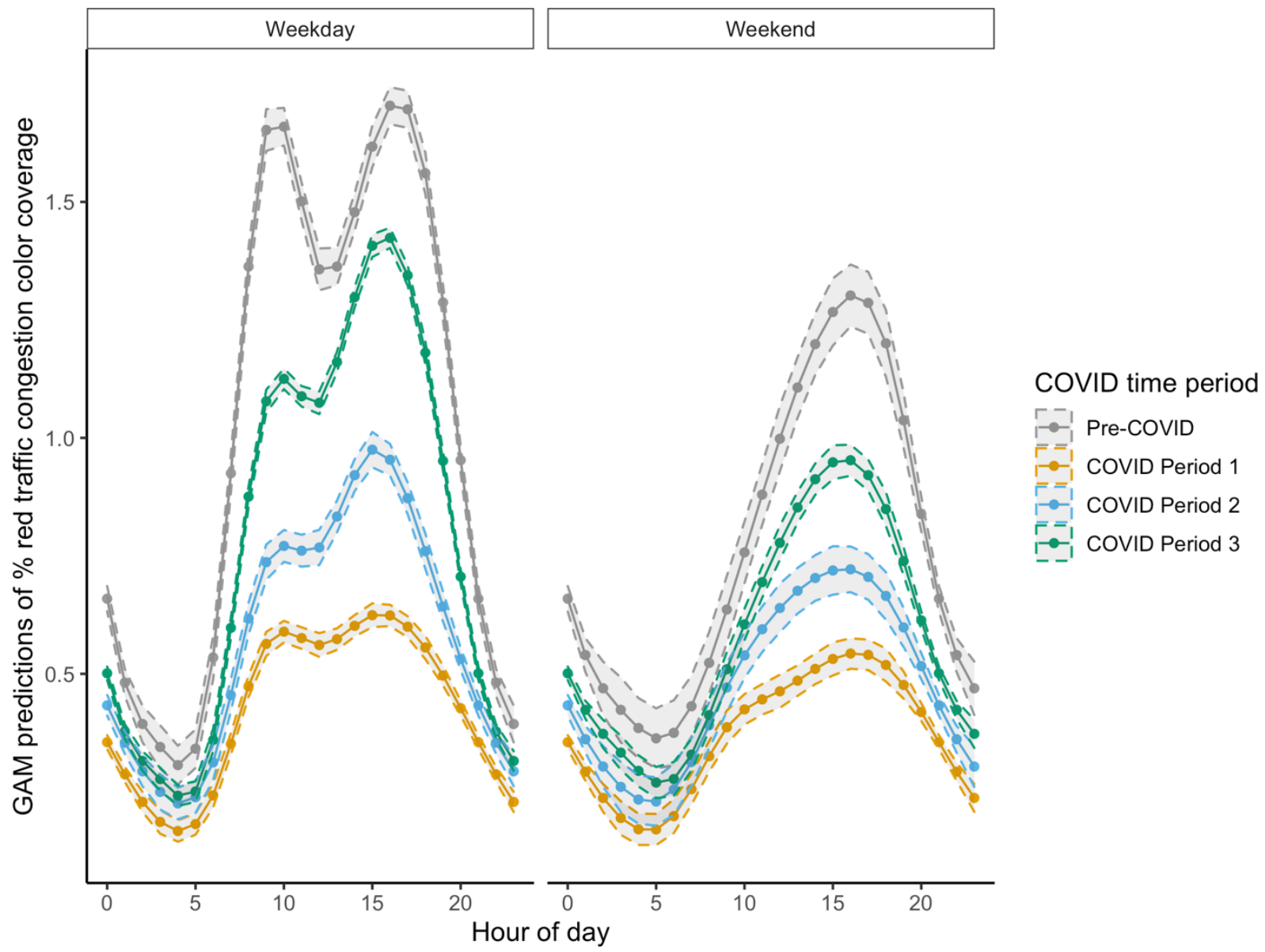

Figure 4. Diurnal fluctuation of red color coverage (in \% area) on the traffic congestion maps for a typical weekday and weekend day (points and solid lines). Typical congestion levels are predicted from the GAM models with 95\% confidence intervals (gray shading surrounding by dashed lines), for each COVID time period. Pre-COVID is from January 1 to March 13, COVID Period 1 is March 14 to May 19, COVID Period 2 is May 20 to June 16, and COVID Period 3 is June 17 to December 31.

A closer inspection of the GAM splines (Supplemental Figure 1), including the deviation of the fitted spline from the intercept, further highlight these differences in diurnal traffic congestion. In Panel C of Supplemental Figure 1, we can see that while the heights of the morning rush hour peak for weekdays remains highest for the Pre-COVID period, for COVID Period 3, the evening rush hour actually has a greater peak than the Pre-COVID period. This shift in traffic from the morning to the evening rush hour results in a diurnal congestion pattern that appears somewhere between the Pre-COVID weekday and weekend distributions. 
medRxiv preprint doi: https://doi.org/10.1101/2021.03.04.21252917; this version posted March 8, 2021. The copyright holder for this preprint (which was not certified by peer review) is the author/funder, who has granted medRxiv a license to display the preprint in perpetuity.

All rights reserved. No reuse allowed without permission.

\section{DISCUSSION}

We present evidence of social-distancing fatigue in Manhattan, NYC, from evaluation of traffic congestion levels during the COVID-19 pandemic. While traffic decreased sharply following the onset of the pandemic and implementation of response policies, levels were already rebounding almost two months before stay-at-home orders ( $N Y$ on PAUSE) were lifted on June 8. Overall, we identified four COVID periods based on traffic congestion patterns. While the dates delineating the COVID period sometimes lined up with the implementation of official social distancing policies, they did not always. For example, traffic congestion began to plummet on March 14, but school closures were not implemented until March 16. NYC bars and restaurants closed in-person service on March 17, and NY on PAUSE began on March 22. The time period during which NY on PAUSE was in effect spans two different COVID Periods because traffic began to rebound far in advance of the first reopening policy (Phase 1 reopening) which occurred on June $8^{\text {th }}$. COVID Period 3, when traffic began to stabilize (June $17^{\text {th }}$ ), was very close to the Phase 2 re-opening date of June 22 (Figure 2). We also observe large impacts of the pandemic on the distribution of traffic throughout the day, such that the pre-pandemic bi-modal weekday diurnal congestion representing the morning and evening rush hour was dramatically depressed. By September, traffic congestion had rebounded to approximately $75 \%$ of pre-pandemic levels.

Dramatic decreases in traffic have been noted in $\mathrm{NYC}^{17}$ and many other places ${ }^{18-21}$ in response to the pandemic, including Padova, Italy ${ }^{18}$ and Auckland, New Zealand. ${ }^{19}$ The study in Padova found a decrease in traffic flow (vehicle counts per unit time) in 2020 of approximately $70 \%$, compared to $2018-2017 .{ }^{18}$ Similarly, the study in Auckland found a $60-80 \%$ decrease in traffic flow following travel restrictions implemented in response to the pandemic. ${ }^{19}$ Another analysis of traffic changes in the NYC metro area found reductions of $66 \%$ in passenger vehicle traffic the week of March 28-April 3.17 While the traffic flows reported by these other studies cannot be directly compared to our metrics, our findings were in line with those previously published. We found a 59\% reduction in total map area covered by traffic congestion during March 14-May 19, compared to January 1-March 13, and we were able to extent our analysis through the end of 2020 .

In this paper, we use changes in traffic as a measure of human mobility and an indicator for social-distancing interventions. However, an increase in traffic congestion does not necessarily correlate with increased case counts of COVID-19, as a study evaluating correlations between traffic and cases in various cities of South Korea found. ${ }^{12}$ Broadly, we can conceptualize COVID-19 non-pharmaceutical interventions in four categories: face mask mandates, isolation or quarantine (including stay-at-home orders), traffic or travel restrictions (such as limiting travel between cities or counties), and social-distancing (closure of schools or other businesses, or limiting gatherings). ${ }^{22} \mathrm{~A}$ review found that social-distancing was the most effective single nonpharmaceutical intervention, while combining social-distancing with at least one other intervention was even more effective. ${ }^{22}$ Traffic congestion can be thought of as an indicator for three of these intervention groupings (all but mask mandates), as human mobility is a component of isolation or quarantine, traffic or travel restrictions, and social-distancing. As such, it makes sense to hypothesize that increased congestion may correlate with increased opportunity for SARS-CoV-2 transmission. However, increases in traffic congestion may also be an indicator of 
a switch in transportation methods in response to the pandemic; studies have documented dramatic decreases in use of public transportation in $\mathrm{NYC}^{23}$ and metro areas in Sweden. ${ }^{24}$ It is possible that individuals who otherwise would have used public transit such as subways or buses are now relying more heavily on private or shared vehicles to reduce their chance of exposure, as was found in Canada. ${ }^{25}$

Understanding changes in traffic congestion during the pandemic is useful not only as a proxy for human mobility, but also for implications on large-scale traffic interventions that may be implemented in the future. For example, in 2019 New York City became the first American city to approve a congestion pricing policy, ${ }^{26}$ with implementation scheduled to begin in early 2021 (although this was delayed). The large-scale traffic disruption that followed implementation of NY on PAUSE, however, may be useful in informing what kinds of changes in traffic patterns could reduce congestion. As we saw in COVID period 1, traffic congestion can be reduced both by depression of overall traffic and by dampening the bimodal diurnal congestion driven by weekday rush hour.

In this paper, use of STL analysis allowed for clear identification of the increasing trend in traffic congestion, while use of GAM models allowed us to account for the changing within-day distribution of the congestion data over the course of the pandemic. These methods allowed us to identify the presence of social-distancing fatigue and to describe traffic changes by hour, demonstrating a clearer picture of the impact of the pandemic on traffic in NYC. This information is useful not only as a proxy for tracking human mobility, but also for understanding how large-scale travel restrictions can impact traffic patterns and congestion overall.

Out study has some notable limitations. First, we include a fairly limited geographic area (the borough of Manhattan, NYC), and thus results of our study may not be generalizable to other areas. However, studies in other cities also find dramatic decreases in traffic, on a similar scale as that reported here. ${ }^{18,19,21}$ Second, our data source does not allow for disaggregation of passenger vehicles and trucks, which were likely differentially impacted by responses to the pandemic (as trucking operations may be considered essential businesses). Studies in $\mathrm{NYC}^{27}$ and Somerville $\mathrm{MA}^{20}$ have found decreases in both vehicles and trucks, though the decrease was substantially less for trucks. Third, we do not disaggregate traffic changes by neighborhoods, and thus do not report variation in congestion changes within Manhattan. We recommend that future studies describe and evaluate these potential differences.

\section{CONCLUSIONS}

Using highly temporally resolved, crowd-sourced traffic congestion data, we describe changes in traffic congestion in Manhattan, NYC, during the COVID-19 pandemic. We report dramatic declines in traffic congestion during the initial stages of the pandemic and implementation of stay-at-home orders, followed by rebounds in congestion nearly two months before stay-at-home orders were reversed, evidence of social-distancing fatigue. Additionally, we describe changes in diurnal traffic congestion patterns for weekdays and weekends, by hour, for four time periods 
medRxiv preprint doi: https://doi.org/10.1101/2021.03.04.21252917; this version posted March 8, 2021. The copyright holder for this preprint (which was not certified by peer review) is the author/funder, who has granted medRxiv a license to display the preprint in perpetuity.

All rights reserved. No reuse allowed without permission.

pandemic, in planning for responses to future pandemics, as well as in understanding the potential impact of large-scale traffic interventions such as congestion pricing policies.

Funding: JAS is supported by NIEHS under award number 2T32ES007322-19. MEM and MH are support by the NSF Award Number 2029421, RAPID: Transmission and Immunology of COVID-19 in the Pandemic and Post-Pandemic Phase: Real-time Assessment of Social Distancing \& Protective Immunity. MH was also supported in part by NIEHS award numbers R21ES030093 and P30ES009089. MEM was also supported by the Office of the Director, National Institutes of Health of the National Institutes of Health under award number DP5OD023100. The funders had no role in study design, data collection and analysis, decision to publish, or preparation of the manuscript.

\section{REFERENCES}

1. Li R, Pei S, Chen B, et al. Substantial undocumented infection facilitates the rapid dissemination of novel coronavirus (SARS-CoV-2). Science. 2020;368(6490):489-493.

2. World Health Organization. COVID-19 Weekly Epidemiological Update. 2020.

3. Tognotti E. Lessons from the history of quarantine, from plague to influenza A. Emerg Infect Dis. 2013;19(2):254-259.

4. Jarvis $\mathrm{Cl}$, Van Zandvoort K, Gimma A, et al. Quantifying the impact of physical distance measures on the transmission of COVID-19 in the UK. BMC Med. 2020;18(1):124.

5. Alagoz O, Sethi AK, Patterson BW, Churpek M, Safdar N. Effect of Timing of and Adherence to Social Distancing Measures on COVID-19 Burden in the United States : A Simulation Modeling Approach. Ann Intern Med. 2020.

6. Moore RC, Lee A, Hancock JT, Halley M, Linos E. Experience with Social Distancing Early in the COVID-19 Pandemic in the United States: Implications for Public Health Messaging. medRxiv. 2020.

7. Zhao SZ, Wong JYH, Wu Y, Choi EPH, Wang MP, Lam TH. Social Distancing Compliance under COVID-19 Pandemic and Mental Health Impacts: A Population-Based Study. Int J Environ Res Public Health. 2020;17(18).

8. Xie W, Campbell S, Zhang W. Working memory capacity predicts individual differences in socialdistancing compliance during the COVID-19 pandemic in the United States. Proceedings of the National Academy of Sciences. 2020;117(30):17667-17674.

9. Charoenwong B, Kwan A, Pursiainen V. Social connections with COVID-19-affected areas increase compliance with mobility restrictions. Science Advances. 2020;6(47):eabc3054.

10. Tizzoni M, Bajardi P, Decuyper A, et al. On the Use of Human Mobility Proxies for Modeling Epidemics. PLOS Computational Biology. 2014;10(7):e1003716.

11. Hilpert $M$, Johnson $M$, Kioumourtzoglou M-A, et al. A new approach for inferring traffic-related air pollution: Use of radar-calibrated crowd-sourced traffic data. Environment international. 2019;127:142-159.

12. Lee H, Park SJ, Lee GR, et al. The relationship between trends in COVID-19 prevalence and traffic levels in South Korea. International Journal of Infectious Diseases. 2020;96:399-407.

13. Wikipedia. Google Traffic. 2017; https://en.wikipedia.org/wiki/Google Traffic.

14. Wood SN. Generalized additive models: an introduction with R. CRC press; 2017. 
medRxiv preprint doi: https://doi.org/10.1101/2021.03.04.21252917; this version posted March 8, 2021. The copyright holder for this preprint (which was not certified by peer review) is the author/funder, who has granted medRxiv a license to display the preprint in perpetuity.

All rights reserved. No reuse allowed without permission.

15. Cleveland RB, Cleveland WS, McRae JE, Terpenning I. STL: A seasonal-trend decomposition. Journal of official statistics. 1990;6(1):3-73.

16. Wood SN. Fast stable restricted maximum likelihood and marginal likelihood estimation of semiparametric generalized linear models. Journal of the Royal Statistical Society (B). 2011;73(1):3-36.

17. Schuman R. INRIX U.S. National Traffic Volume Synopsis: Issue \#2 (March 21-27, 2020). 2020.

18. Rossi R, Ceccato R, Gastaldi M. Effect of Road Traffic on Air Pollution. Experimental Evidence from COVID-19 Lockdown. Sustainability. 2020;12(21):8984.

19. Patel H, Talbot N, Salmond J, Dirks K, Xie S, Davy P. Implications for air quality management of changes in air quality during lockdown in Auckland (New Zealand) in response to the 2020 SARSCoV-2 epidemic. Science of the Total Environment. 2020;746:141129.

20. Hudda N, Simon MC, Patton AP, Durant JL. Reductions in traffic-related black carbon and ultrafine particle number concentrations in an urban neighborhood during the COVID-19 pandemic. Science of The Total Environment. 2020;742:140931.

21. Parr S, Wolshon B, Renne J, Murray-Tuite P, Kim K. Traffic Impacts of the COVID-19 Pandemic: Statewide Analysis of Social Separation and Activity Restriction. Natural Hazards Review. 2020;21(3):04020025.

22. Bo Y, Guo C, Lin C, et al. Effectiveness of non-pharmaceutical interventions on COVID-19 transmission in 190 countries from 23 January to 13 April 2020. International Journal of Infectious Diseases. 2021;102:247-253.

23. Sy KTL, Martinez ME, Rader B, White LF. Socioeconomic disparities in subway use and COVID-19 outcomes in New York City. medRxiv. 2020:2020.2005.2028.20115949.

24. Jenelius E, Cebecauer M. Impacts of COVID-19 on public transport ridership in Sweden: Analysis of ticket validations, sales and passenger counts. Transportation Research Interdisciplinary Perspectives. 2020;8:100242.

25. Labonté-LeMoyne É, Chen S-L, Coursaris CK, Sénécal S, Léger P-M. The Unintended Consequences of COVID-19 Mitigation Measures on Mass Transit and Car Use. Sustainability. 2020;12(23):9892.

26. Durkin E, Aratani L. New York becomes first city in US to approve congestion pricing. The Guardian. April 1, 2019.

27. Gao J, Wang J, Bian Z, et al. The Effects of the COVID-19 Pandemic on Transportation Systems in New York City and Seattle, USA. arXiv preprint arXiv:201001170. 2020. 